\title{
CORRIGENDUM
}

\section{Nanoemulsion of eucalyptus oil and its larvicidal activity against Culex quinquefasciatus - CORRIGENDUM}

\section{S. Sugumar, S.K. Clarke, M.J. Nirmala, B.K. Tyagi, A. Mukherjee and N. Chandrasekaran}

doi: 10.1017/S0007485313000710, Published by Cambridge University Press, 9 January 2014.

The authors apologise for errors in the original version of this article. Figures 2 and 4 were transposed in error. The figures and their correct captions are given below.

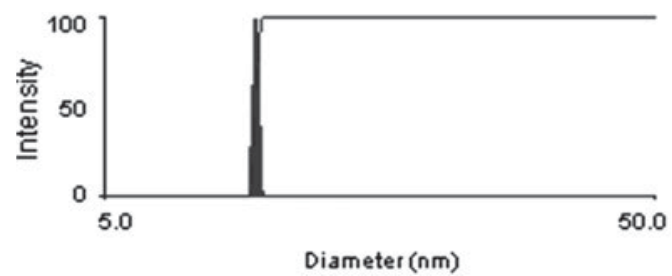

Fig. 2. A typical particle size distribution measurement by dynamic light scattering.
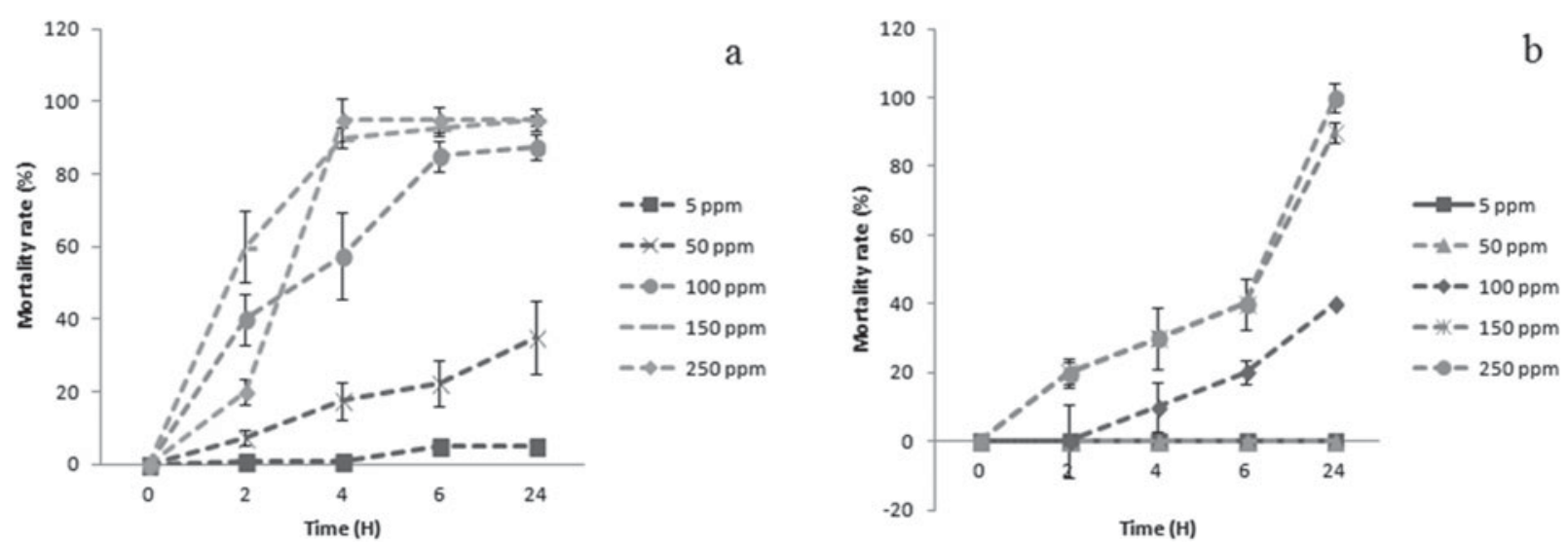

Fig. 4. (a) Mortality rate of eucalyptus oil nanoemulsions against $C x$. quinquefasciatus and (b) Mortality rate of eucalyptus oil bulk emulsion against $C x$. quinquefasciatus.

\section{Reference}

Sugumar, S., Clarke, S.K., Nirmala, M.J., Tyagi, B.K., Mukherjee, A., and Chandrasekaran, N. Nanoemulsion of eucalyptus oil and its larvicidal activity against Culex quinquefasciatus. Bulletin of Entomological Research. Published by Cambridge University Press, 9 January 2014. doi:10.1017/S0007485313000710. 